\title{
Formation of a marketing support complex for an export-oriented enterprise in conditions of risk and uncertainty
}

\author{
Olga Maslak $^{1,{ }^{*}}$, Petro Sokurenko ${ }^{2}$, Natalya Grishko ${ }^{3}$ and Mariya Maslak $^{4}$ \\ ${ }^{1}$ Doctor of Economics, professor, Kremenchuk Mykhailo Ostrohradskyi National University, Ukraine \\ ${ }^{2} \mathrm{PhD}$, associate professor, Affiliate «Kremenchuk institute of Higher Educational Establishment \\ «Alfred Nobel University», Ukraine \\ ${ }^{3} \mathrm{PhD}$, associate professor, Kremenchuk Mykhailo Ostrohradskyi National University, Ukraine \\ ${ }^{4} \mathrm{PhD}$, associate professor, National Technical University «Kharkiv Polytechnic Institute», Ukraine
}

\begin{abstract}
The work covers the theoretical and methodological foundations of marketing for an export-oriented enterprise. At the present stage of development of the economy, the use of marketing tools in activities is a powerful means of increasing the enterprises ' competitiveness, strengthening adaptive characteristics when external conditions and market conditions change. Consumption volumes are the driving force of the production activity of the enterprise, affecting the nomenclature, range and scale of production. The introduction of the marketing concept, which focuses on the production of products that are in the market demand, stimulates the production of products needed by the consumer. Theoretical and methodological issues of marketing aimed at restricting the demand for irrational demand products (opposing marketing) attract the attention of scientists and practitioners. At the same time, the choice of the topic was due to insufficient research of this scientific problem as a whole and its relevance for the economy of Ukraine, especially in the context of the development of cooperation with the European Union. A detailed study of the tools of opposing marketing allows export-oriented enterprises to ensure the profitability of commercial and marketing activities, while the harmful effects of the consumption of goods of irrational demand determine the feasibility of research and analysis of the conditions and their consumption motivation. The demand for these products is undesirable; therefore, countermeasure marketing at the state level is controlled by the relevant organizations.

In this study, attention is paid to the analytical and regulatory aspects of determining the current state and trends of marketing support for the tobacco industry enterprises activities. The features of a complex of marketing support formation of their activities in the conditions of risk and uncertainty are determined.
\end{abstract}

Key words: marketing, marketing support, management, model, marketing technologies, complex, irrational demand

\footnotetext{
*Corresponding author: 2nata.grishko@gmail.com
} 


\section{Introduction}

Marketing should be taken as a study of customer needs, characteristics of consumer demand, work with target segments to generate potential demand. Marketing support of the tobacco industry has certain features, based on the properties of products related to products of irrational demand (harmful and socially dangerous goods). Tobacco products as goods are characterized by specialty of implementation, which is used in the development of the marketing complex, namely, social and ethical marketing in the tobacco market.

The main stages of the study were formed to assess the trends and opportunities for international, particularly:

- analytical and regulatory aspects of current state determination and trends of marketing support for the activities of export-oriented enterprises;

- determination of the formation specifics of a marketing complex for irrational demand goods producers, in particular: the establishment of legislative restrictions on tobacco advertisements in EU countries; justification of the model creation of a marketing information system in the enterprise.

\section{Data and Methods}

The aim of the study is to develop a methodological approach and practical recommendations for finding and implementing ways to improve the marketing mechanism of an export-oriented enterprise under conditions of risk and uncertainty of the market of goods with irrational demand.

The solution of the set tasks was carried out using the following methods: theoretical generalization - to study and systematize theoretical approaches for the definition and justification of the problem studied; analysis and synthesis - to determine the object and subject of research; graphic; mathematical statistics - when establishing the dependence of the integral performance index of the marketing complex; method of multi-criteria optimization - when modeling the costs of implementing the marketing complex in a particular market.

Information base selected materials of official publications of the State Statistics Committee, domestic and foreign scientific literature data, primary reporting enterprises documentation data, annual financial and statistical reporting.

\section{Results}

\subsection{Analytical and regulatory aspects of determining the current state and marketing supportive trends for the tobacco industry enterprises' activities}

Sales promotion is a set of techniques to increase sales. Features of products or services determine the use of incentives and the choice of a specific channel to promote products, the use of logistics supply intermediaries, a combination of several distribution channels, which forms a specific distribution system.

Thus, effective marketing provides the groundwork for a profitable enterprise; while the marketing complex forms an individualized system, which affects the performance of the enterprise through the product (product), price (price), place (distribution) and promotion.

According to the legislative acts of Ukraine - tobacco goods - products fully or partially made from tobacco leaf as a raw material, prepared in such a way as to be used for smoking, sucking, chewing or smelling: filter or non-filter cigarettes, cigarettes, cigars, 
cigarillos, as well as pipe, snuff, sucking, chewing tobacco, tobacco and other products made of tobacco or its substitutes for smoking, smelling, sucking or chewing [1].

The development of conversion marketing activities that are used by manufacturers of irrational demand should be preceded by a detailed study of the production and sale of tobacco products. Products of irrational demand are also targeted marketing. The ban on smoking in public places and establishments as well as the trend of rising prices for tobacco products and alcoholic beverages, have affected the decrease in sales volumes and, consequently, their production volumes in Europe and the USA. In Ukraine, the decline in production was observed during 2016-2017, while the production volumes in the processing industry had a positive trend. The wave of growth in the production of tobacco products was characterized by the period from 2009 to 2013 , the next wave was observed during 2014-2016. The production of tobacco products in Ukraine in 2007-2017 data is shown in Fig. 1.

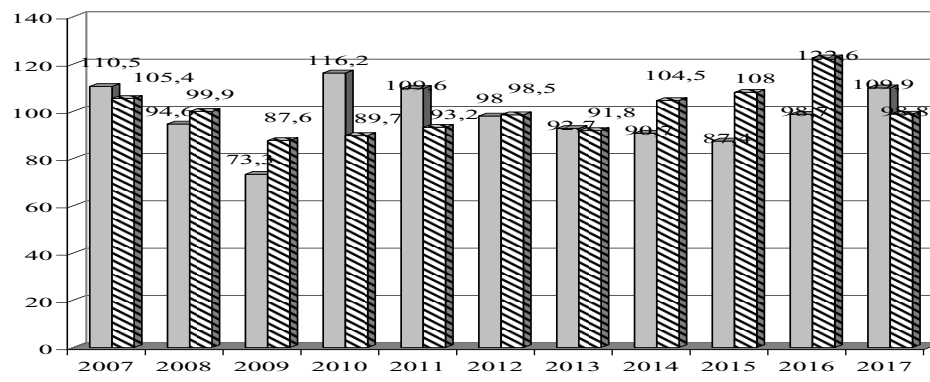

$\square$ Processing industry
$\square$ Tobacco production

Fig. 1. Indices of tobacco production in Ukraine (percent to previous year) Source: Formed by authors based on [2].

Since the 1990s, tobacco production has been characterized by trends of creation joint ventures with international and world-renowned corporations. The creation of joint ventures covered $95 \%$ of the production of tobacco factories in Ukraine. All this is primarily due to the fact that Ukraine was among the top 20 countries in terms of tobacco consumption. The prices of tobacco products corresponded to the waves of consumer price indices for goods during 2002-2016, while the general trend was growing. Producer price and consumer price indices for individual product groups are shown in Fig. 2.

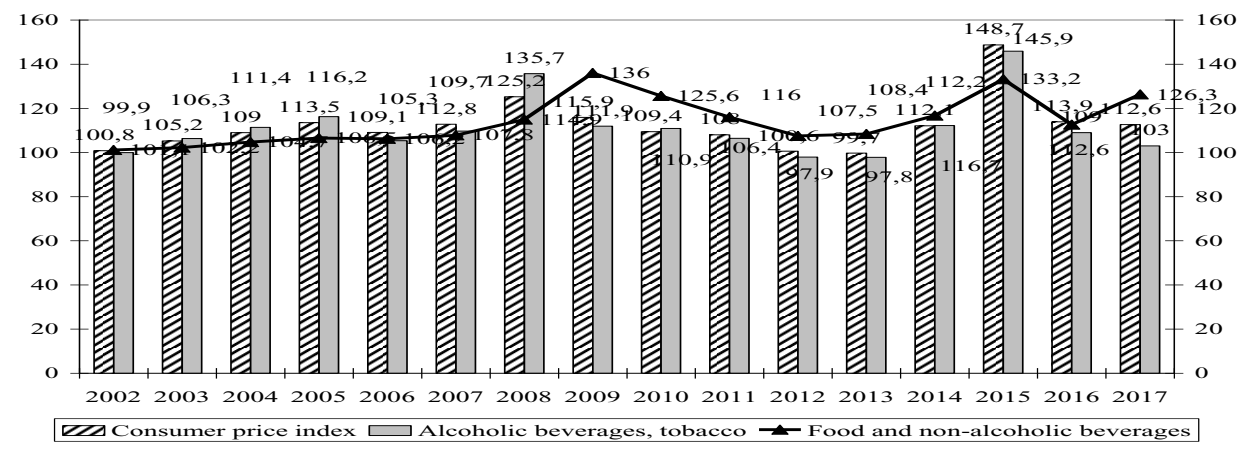

Fig. 2. Consumer price indices for goods (including tobacco products) in 2002-2017 Source: Formed by authors based on [2].

During the 2009-2012 there was a gradual increase in the growth rate of the physical volume of tobacco products (retail turnover of enterprises in Ukraine) from $79.1 \%$ to 
$143.5 \%$, respectively. 2012 is a turning point. During 2012-2016 there is a decrease in the pace of retail turnover of enterprises in Ukraine. The growth rate of production of tobacco products - in 2016, production volume amounted to $122.6 \%$ of the volume of 2015 ; and consumption in the retail commodity networks of Ukraine $-95.1 \%$ of the previous period, that is, domestic consumption declined amid production growth, focusing on the exportoriented nature of sales.

In 2017 , tobacco products produced $98.8 \%$ of 2016 , nevertheless, at the end of the research period, prices for alcoholic beverages and tobacco products increased by $26.3 \%$. When developing a toolkit for conversion and opposing marketing, it should be borne in mind that the most part of tobacco products is sold through retail chains, having certain specific features. This market has an oligopolistic character next to the underdevelopment of the domestic raw material base of fermentation and tobacco enterprises.

Tobacco products manufacturers work on imported raw materials. Among the main producers, which hold the main market share, the following should be highlighted: CNTC (China) - 33.7\%, Altria (USA) - 17.6\%, British American Tobacco (USA) - 15.1\%, "Imperial Tobacco (UK) - 3.6\% and other companies - 30\% [3].

Enterprises producing tobacco products - Philip Morris Ukraine, PJSC "JT International Ukraine" sell some of the products for export, which requires them to take into account the requirements of the legislation for implementation in EU markets, EU legal norms

- restriction in advertising products, in particular irrational demand;

- restriction in advertising non-prescription medical drugs;

- Requirements for quantitative parameters of commercials

- the use of personal data for individual advertising.

Fig. 3 shows some legal restrictions on certain types of goods in EU countries (convention adopted by 18 countries) [4].

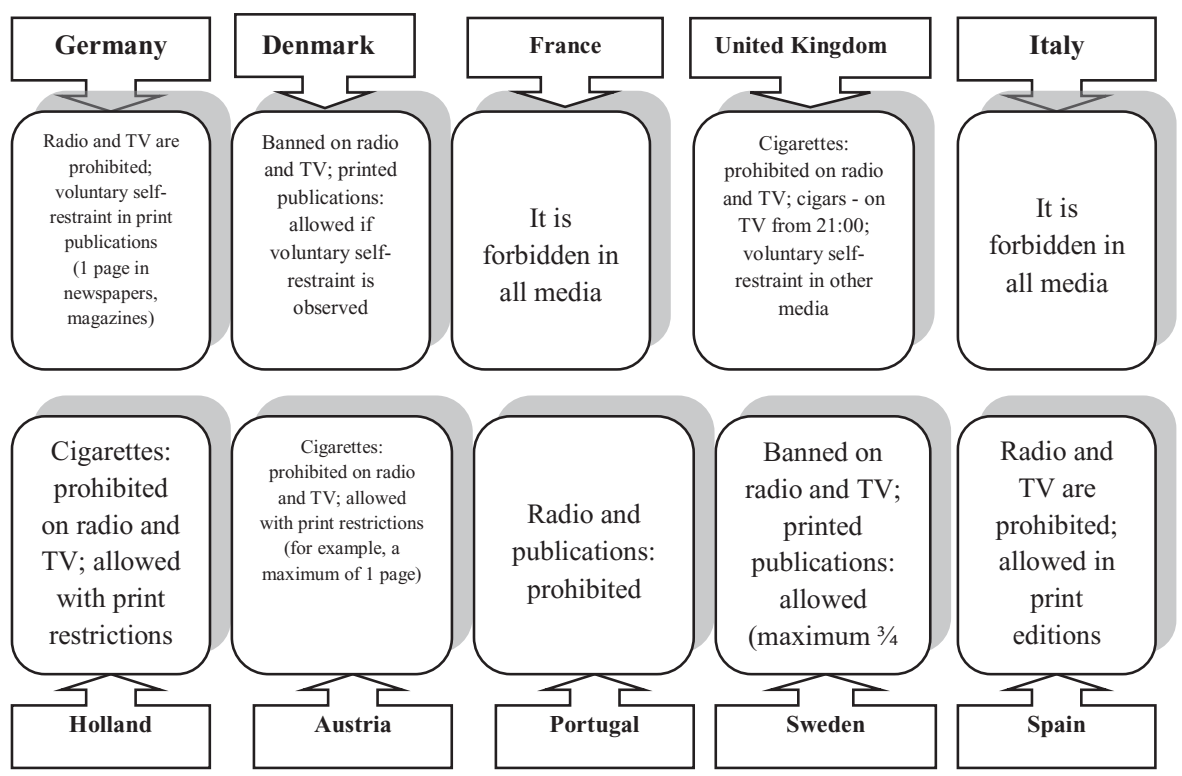

Fig. 3. Legal restrictions on tobacco advertising in EU countries

Source: Formed by authors based on [4].

When entering the external market, in particular the EU market, it is necessary to take into account the requirements of the convention of the European (international) television, which formulate provisions for ethical standards when promoting and advertising products. 
The content of advertising products must also pass through the advertiser's self-control as required by the domestic market.

Thus, the socio-ethical marketing of tobacco production enterprises should take into account the opposing marketing by the state and society, based on social responsibility, which will ensure the profitability of the activity while maintaining a positive reputation in the market. In summary, the marketing complex for irrational demand goods producers should be formed, taking into account legislative restrictions on the markets for sales in the sphere of pricing regulation, sales and promotion features.

\subsection{Prerequisites for the formation of a marketing information system model in an enterprise}

An analysis of the current state and characteristics of the development of the tobacco industry in Ukraine showed that enterprises were reoriented to sell products on foreign markets, with the majority of enterprises being reorganized into joint ventures with a foreign capital share. So, PJSC "JT International Ukraine" is a member of Japan Tobacco group of companies, a leading international manufacturer of tobacco products, produces more than 90 brands of cigarettes, and three of them are among the five most popular in the world. JTI is represented in 120 countries and has over 25,000 employees. The company's headquarters is located in Geneva, Switzerland. During the research period, there is a positive trend in sales volumes, in particular for export. But, by the end of 2017, sales volumes decreased by $14.44 \%$, which is associated with a decrease in sales, primarily in the domestic market. In 2014 - 2017 the share of sales for exports gradually increased from $42 \% ; 52 \% ; 52.18 \%$ to $56.6 \%$. Sales of products have a seasonal nature, with the main sales markets being the regions of the CIS and the Caucasus, Georgia, the main sales channels are indirect distributor channels. The restriction on introducing innovative types of products is due to a ban on advertising tobacco products, which increases the riskiness of new products entering the market. Legislative restrictions on advertising and selling tobacco products are leveled by the entry of enterprises into markets with milder terms of regulation. Promotion of products for export takes place through contractors, in the domestic market - through the customer service department. The raw material base is the countries of Asia and the EU.

The implementation of marketing functions in order to improve the efficiency of the enterprise is carried out within the framework of marketing support of PJSC "JT International Ukraine". The implementation of management functions combines the following procedures: production planning for market needs; development of new types of products in the framework of the expansion of the range; introduction of process innovations, entry into new markets, the formation of effective well-established logistics supply chains, order fulfillment for profit. The customer service department of PJSC "JT International Ukraine" is responsible for the formation of a communication network and establishing connections with customers in the domestic market. In order to strengthen the marketing component in ensuring the effectiveness of the enterprise, it is advisable to consider a group of indicators that will help more effectively reflect its level when calculating the integral indicator [5].

The results of diagnostics of the marketing complex of PJSC "JT International Ukraine" are illustrated in fig. 4.

The negative dynamics of the integral indicator of marketing support of the enterprise at the end of 2017 is primarily due to shortcomings in the strategic planning of the company's marketing activities. It is also necessary to consider indicators that have a quantitative dimension. The first group of indicators in accordance with the complex of marketing refers to the element "Product". This group may include indicators reflecting various aspects of 
this element: width, depth, harmony and saturation of the range; coefficient of rationality of the assortment structure; the stage of the life cycle on which each assortment of goods is located; profitability of products and individual commodity groups; the number of new types of products that have replenished the commodity nomenclature; quality of products in terms of incoming complaints from consumers, etc. Among the most significant marketing tools used by the enterprise is a combination of subsystems "goods", "price policy", "sales channel", "distribution system".
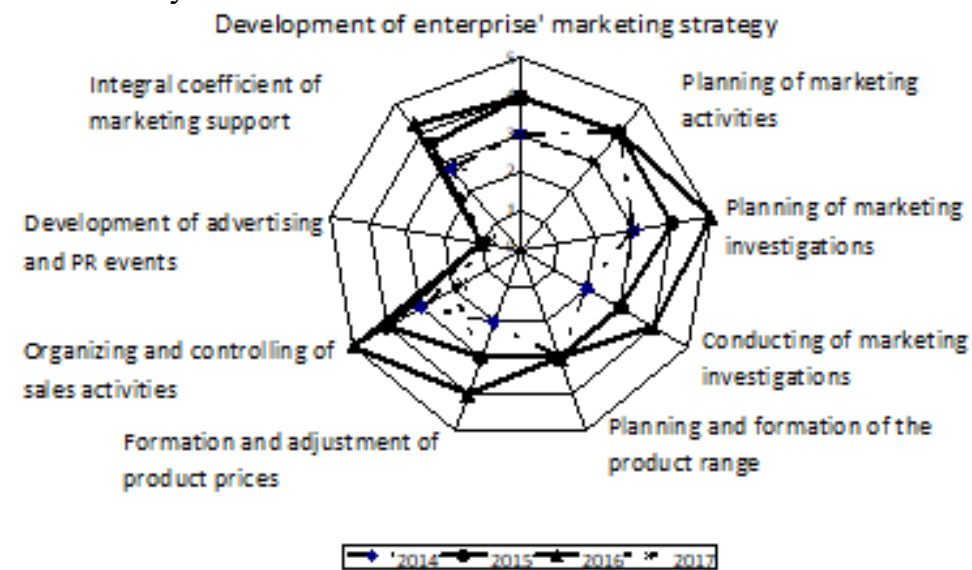

Fig. 4. The level of marketing support of PJSC "JT International Ukraine" for 2014-2017 Source: Formed by authors based on [6].

The peculiarities of promotion of such goods as tobacco products, which is a product of irrational demand, should be taken into account. Next to the marketing activities that the company implements, there is a system of counteracting marketing by the society and the state. That is, PJSC "JT International Ukraine", together with a focus on maximizing profits, which should not lose its reputation in the market and is obliged to maintain social responsibility and social and ethical standards in promoting products. Thus, the state, implementing measures to regulate the activities of enterprises producing alcoholic and tobacco-containing products, limits the amount of irrational demand. Along with the implementation of conversion and countering marketing activities, the company's marketing services must provide high sensitivity to trends and rates of change in the market, assess the adequacy of the internal environment of the enterprise to new tasks and exercise powerful information influence in moving the company in a strategically chosen direction. Effective indicators of the integral model of assessing the performance of PJSC "JT International Ukraine" by the functional components of the elements of the marketing complex are shown in Table 1. The calculation of the integral indicator was based on the standardization procedure (standardization) of the selected indicators [6] for comparability of the evaluation base.

Determination of the level and dynamics of the integrated performance index of PJSC "JT International Ukraine" in terms of the functional components of the marketing complex, depending on the evaluation criteria during 2014-2017, allows to note 2016 as the best in terms of ensuring effectiveness. This doubtful state is observed during 2014 and 2017. To strengthen the marketing component in the performance of the enterprise, a group of indicators that help to more effectively reflect its level when calculating the integral indicator is considered. The results show that PJSC "JT International Ukraine" is in a state of considerable dependence on the means of regulating behavior on the market: further legislative measures to ban smoking, advertising and distribution of tobacco products. 
The effectiveness of the sales activity of the production enterprise depends on the ability to predict the influence of relevant factors on the level of the integral performance index of the marketing complex, possibly using information support systems to solve problems of effective information interaction with market actors, expanding the information base for making management decisions. 


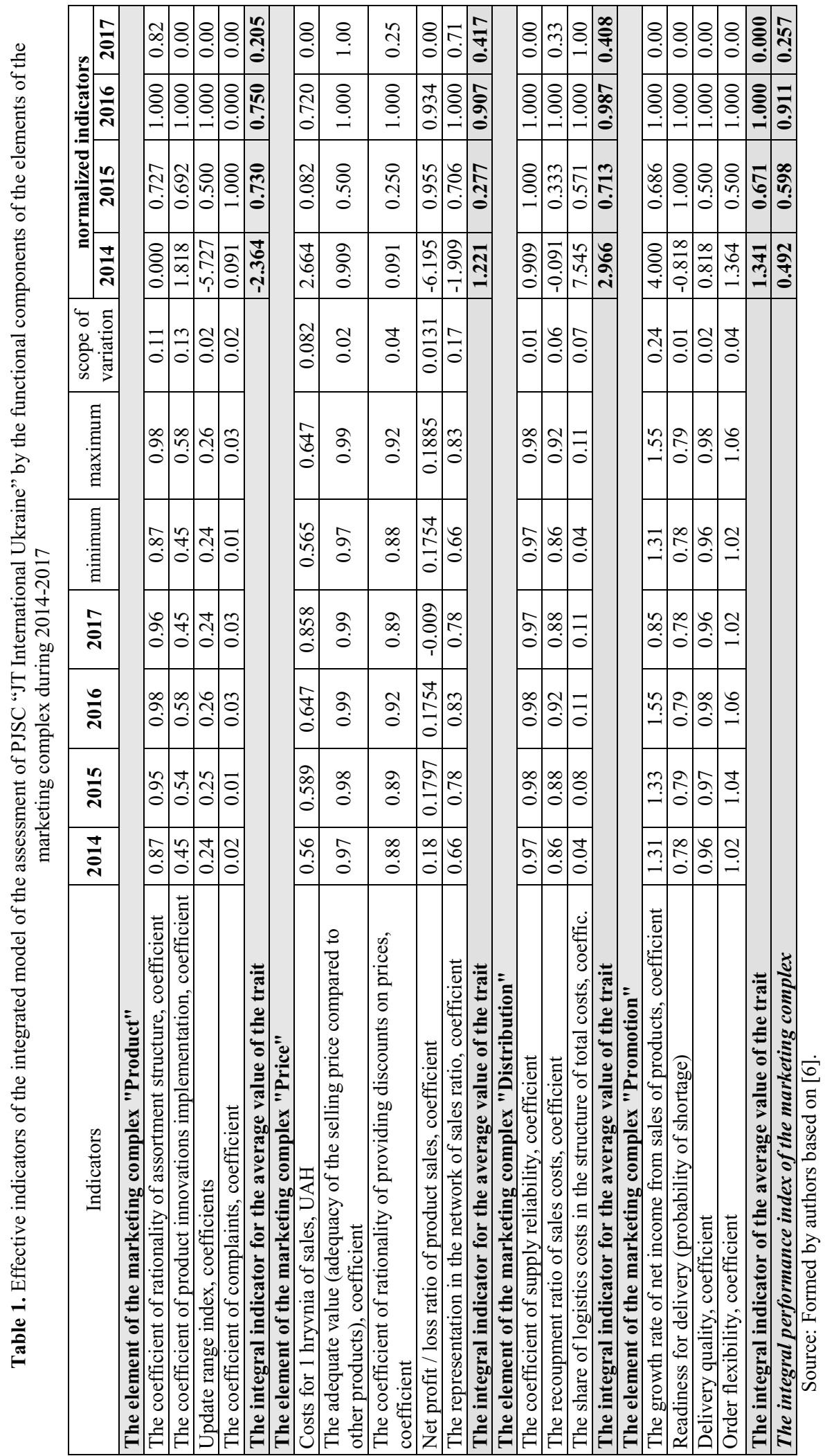


Thus, the establishment of the above dependence allows us to form an analytical conclusion about the mechanism of ensuring the effectiveness of marketing activities of PJSC “JT International Ukraine". Consequently, an increase in the value of an enterprise among consumers, an increase in the efficiency of marketing processes (implementation and adaptation) will help adjust the management of an enterprise so that it acquires economic growth. PJSC "JT International Ukraine" has the goal of achieving sales performance, the important factors of which are precisely the volume of sales and the competitiveness of the enterprise.

\section{Discussion}

The implementation of information technology into the marketing management system is associated with the need to facilitate and accelerate the perception of the array of primary empirical information about the activities of the enterprise, to increase its effectiveness.

The implementation of a marketing information system in an enterprise involves the implementation of the following steps:

1. Determining the dependence of the integral performance index of the marketing complex on relevant factors;

2. Formation of an optimization model for managing the performance of the marketing activity of the enterprise and developing the algorithm for its solution in the conditions of the existing enterprise of PJSC "JT International Ukraine" using the PPP MS Excel;

3. Modeling of the costs for the marketing complex realization in a specific market for PJSC "JT International Ukraine" [7].

Stage 1. To assess the future results of marketing activities, in particular, in individual markets, which characterize the characteristics of sales activities of PJSC "JT International Ukraine", it is possible to use a multifactorial regression equation, in which the indicator reflecting the results of the marketing complex plays the role of a dependent variable, comprehensively characterizes its effectiveness as a target function.

The level of the integral performance index of the marketing complex is influenced by both material and non-material factors. To the most significant material factors we assign in the executed research the share of sales expenses in the total costs of the enterprise.

The specification in the economic-mathematical model of indicate values gives grounds for evaluating the directions of using attracted funds and the probability of obtaining the expected income from the money invested in the development of the enterprise.

1. dependent variable (value of the objective function) - the level of the integral performance index of the marketing complex, coefficient $(\mathrm{Y})$,

2. the most significant factors that affect it differently: export / domestic sales ratio, coefficient $\left(\mathrm{x}_{1}\right)$, update range index, coefficient $\left(\mathrm{x}_{2}\right)$, the share of distribution costs in the total costs of the enterprise, coefficient $\left(\mathrm{x}_{3}\right)$, costs $1 \mathrm{UAH}$, sold products, $\mathrm{UAH}\left(\mathrm{x}_{4}\right)$, the turnover ratio of funds in the calculations $\left(\mathrm{x}_{5}\right)$, the integral coefficient of marketing support activities $\left(\mathrm{x}_{6}\right)$.

Stage 2. The proposed methodology was applied for the enterprise of PJSC "JT International Ukraine" (Table 2).

The calculated value of the criterion is $\mathrm{F}_{\text {calc }}=564,974$, and the critical one for $\mathrm{P}=0.99$, $\mathrm{k}_{1}=6, \mathrm{k}_{2}=4$ is 6.09 . Since $\mathrm{F}_{\text {calc }}>\mathrm{F}_{\text {tabl }}$, with reliability $\mathrm{P}=0.95$ we can assume that the adopted mathematical model is adequate to the experimental data and can be used for economic analysis and forecast [8].

To identify the relationship between indicators of a multifactorial regression model of indicators of influence on the level of the integral performance index of the marketing complex of PJSC "JT International Ukraine", estimates of the model parameters, 
coefficients $a_{0}, a_{1}, a_{2}, a_{3}, a_{4}, a_{5}, a_{6}$ were found. The required sums and the sample mean " $y$ " and " $x$ " were calculated using the appropriate master functions. Thus, we can conclude that the impact of the share of sales expenses in the total expenses of the enterprise and the ratio of marketing support to the integral performance index of the marketing complex of PJSC "JT International Ukraine" is positive and significant. An increase in the index of the renewal of the range does not lead to an increase in the integral index of the effectiveness of the marketing complex, which characterizes the stability of habits and certain conservatism of consumers [9].

Table 2. Multi-factor regression model of indicators of influence on the level of the integrated performance index of the marketing complex of PJSC "JT International Ukraine"

\begin{tabular}{|c|c|c|c|c|c|c|c|}
\hline & \multicolumn{7}{|c|}{ Value } \\
\hline $\begin{array}{c}\text { Index } \\
\text { Evaluation of multiple linear } \\
\text { regression parameters }\end{array}$ & $\begin{array}{c}\mathrm{a}_{6}= \\
0.971\end{array}$ & $\begin{array}{c}\mathrm{a}_{5}= \\
0.470\end{array}$ & $\begin{array}{c}\mathrm{a}_{4}= \\
-2.242\end{array}$ & $\begin{array}{c}\mathrm{a}_{3}= \\
11.522\end{array}$ & $\begin{array}{c}\mathrm{a}_{2}= \\
-3.135\end{array}$ & $\begin{array}{c}\mathrm{a}_{1}= \\
3.743\end{array}$ & $\begin{array}{c}\mathrm{a}_{0}= \\
0.453\end{array}$ \\
\hline $\begin{array}{c}\text { Standard deviations of parameter } \\
\text { estimates }\end{array}$ & 0.203 & 0.089 & 0.760 & 6.641 & 5.464 & 1.335 & 1.939 \\
\hline
\end{tabular}

\begin{tabular}{|c|c|c|}
\hline $\begin{array}{c}\text { The coefficient of determination } \\
\mathrm{R}^{2}=0.999 \\
\end{array}$ & \multirow{2}{*}{\begin{tabular}{|c} 
Standard deviation of \\
the indicator \\
$\mathrm{S}=0.027$
\end{tabular}} & \multirow{3}{*}{$\begin{array}{c}-0.453+3.743 X_{1}--3.135 X_{2}+11.522 X_{3} \\
-2.242 X_{4}+0.470 X_{5}+0.971 X_{6}\end{array}$} \\
\hline $\begin{array}{l}\text { The calculated value of } \mathrm{F} \text { - statistics } \\
\qquad \mathrm{F}_{\text {calc }}=564,974\end{array}$ & & \\
\hline $\begin{array}{l}\text { he sum of the squares of the deviation } \\
\text { f the calculated values from its averag } \\
\text { value }=2.860\end{array}$ & $\begin{array}{c}\text { esidual sum of square } \\
=0.001\end{array}$ & \\
\hline
\end{tabular}

Source: Formed by authors based on [6].

So, the established dependencies allow us to set a range of relevant factors of influence on the performance of the enterprise marketing activity and are the basis for modeling the marketing complex costs on a specific market for PJSC "JT International Ukraine".

Stage 3. Modeling the costs for the realization of marketing complex on a specific market for PJSC "JT International Ukraine". We enter the source data (limiting factors) necessary for building the model in a table created using Excel spreadsheets and the "Search for Solution" add-in. Choose the amount needed to conduct research in a particular market, the total cost of material costs for marketing, the value of which does not go beyond the established limits. We set the conditions necessary to solve the problem. We receive the table which is presented in Fig. 5. 


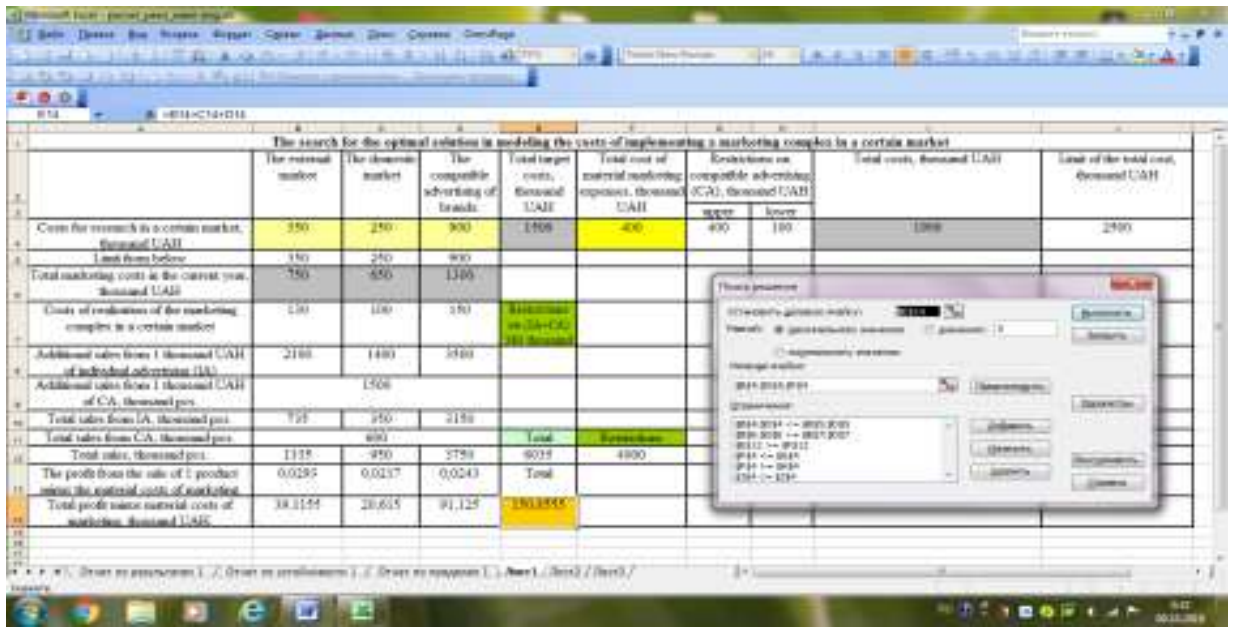

Fig. 5. Construction of source data table using Excel application and limitations for finding the optimal solution in modeling the costs of implementing a marketing complex in a specific market for PJSC "JT International Ukraine"

Source: Formed by authors based on [6].

After fulfillment of modeling the expenditure volume for realization of marketing complex in a particular market by building an optimization model in Excel "Search for Solution", and after analyzing the results, we can draw the following conclusions: an increase of the costs for the realization of marketing complex is effective for the enterprise, as the expenditure amount of 1,900 thousand UAH will bring it additional gross income.

\section{Conclusion}

Consequently, increasing the awareness of the activities and products of the enterprise among consumers, the formation of a positive reputation will help in adjusting the management of the enterprise so that it strengthens its market position. PJSC "JT International Ukraine" has the goal of achieving increased sales profitability, the most important factors of which are precisely the growth rates of sales volumes and increasing the competitiveness of the enterprise. Evaluation of the cost-effectiveness of the marketing complex realization $\mathrm{c}$ is a task, which solution depends on the correctness of the selected criteria and evaluation methods. At the same time, methods and means of influence are chosen; an expenditure budget is drawn up for the implementation of the marketing complex into a certain market. The company is facing an alternative: either to reject a number of goals as unattainable due to the insufficiency of the allocated funds, or, as agreed, to increase the estimated costs. For a reasonable decision about the tactics and strategy of marketing activities of the enterprise, it is important to evaluate the budget and reserve fund of the campaign. This can be done using the model that is proposed for implementation.

It should be emphasized, that the marketing complex for producers of goods of irrational demand must be formed with due regard for account legal restrictions on the markets for implementation in the sphere of pricing regulation, sales and promotion specificities. 


\section{References}

1. S. Anholt, Competitive Identity: The New Brand Management for Nations. Cities and Regions, 732, (2007)

2. The State Statistics Service of Ukraine [online], Available at: www.ukrstat.gov.ua/ (2018)

3. Eurostat Statistics Explined [online], Available at: http://ec.europa.eu/ eurostat/statistics-explained/index.php/ (2018)

4. The Global Comhetitiveness Report, World Economic Forum [online], Available at: www.weforum.org (2016)

5. O. Maslak, N. Grishko, O. Hlazunova, K. Vorobiova, Approaches to the management of the costs of innovation activity of mining enterprises: aspects of economic security. Scientific Bulletin of National Mining University, 5, 137-145, (2017)

6. Annual financial statements of enterprises, Stock market infrastructure development agency of Ukraine (SMIDA) [online], Available at: www.smida.gov.ua/ (2018)

7. E. Dmitruk, Possibilities of model of the enterprise's reputation influence on its economic safety. Project management and production development, 4(32), 152-159, (2009)

8. E. Boulianne, Empirical analysis of the reabilite and validity of balanced scorecard measures and dimensions. Edvances in Management Accounting, 15, 127-142, (2006)

9. Z. Iaremko, G. Tkach, Concerning the national branding in Ukraine in the context of promoting its interests in the world. Young, 40(12.1), 1035-104,0 (2016) 